\title{
Modelling nominal debt contracts and fixed rate debt
}

\author{
Liam Graham* and Stephen Wright ${ }^{\dagger}$
}

12 M ay 2004

\begin{abstract}
A bstract
We provide a simple model of sticky nominal debt contracts and fixed rate debt that can easily be embedded in a dynamic general equilibrium framework. Once linearised, the debt process increases the order of autoregressive dynamics in the system by one; thus potentially introducing more complex adjustment processes.
\end{abstract}

Keywords: nominal debt; dynamic general equilibrium.

J EL Classifications: E30, E44

${ }^{*}$ Corresponding author: Department of Economics, University of Warwick, Coventry, CV 4 7AL, UK; tel: +44 247652 8418; email: L.M.Graham@warwick.ac.uk

${ }^{\dagger}$ Department of E conomics, Birkbeck College, University of London, Malet Street, London W 1E 7HX, UK; tel: +44 207631 6448; email: SWright@econ.bbk.ac.uk 
This paper presents a simple model of nominal debt contracting that can be readily incorporated into a dynamic general equilibrium framework. Our motivation for so doing is based on the following observations:

1. Collateralized nominal debt contracts are the norm in most countries with reasonably stable inflation

2. Adjustments to such contracts are relatively costly, and hence relatively infrequent

3. Many such nominal contracts are written on a "fixed rate" basis

Although a number of papers examine dynamic general equilibrium models with nominal debt (e.g. Aoki et al (2002)) very little attention has been paid to the stickiness of such contracts. Yet nominal debt stickiness is arguably easier to understand than product price stickiness. A well-known criticism of the standard model of product price stickiness is that the "menu costs" that ultimately must generate stickiness are unlikely to be large. In the case of debt contracts, in contrast, the costs of adjustment may well be distinctly larger, since typically this will involve re-assessment of collateral or other features of creditworthiness.

Of course, if the nature of debt contracts is to have first-order effects, some households face (or act as if they face) a binding credit constraint. A comprehensive discussion of this issue can be found in Mankiw (2000).

\section{Financial institutions}

Financial institutions make loans to households based on nominal contracts. We assume that debt contracts are sticky in nominal terms. To capture this in a tractable way, we progress by analogy to Calvo's (1983) model of the aggregate price level. We assume a constant probability $\phi$ that any given debt contract will be adjusted in the next period, with complete adjustment towards its optimal value if adjustment does take place.

The key point is that households facing a binding credit constraint will always accept any new debt that financial institutions offer them. This means that, at least in some neighborhood of a steady state in which the credit constraint binds, we can model the level of debt as determined by financial institutions. 
Following Kiyotaki and Moore (1997) we assume that lenders cannot force borrowers to repay their debts unless they are secured. The optimal value of debt is then given by some constant fraction (which we normalize to unity) of households' collateral $K$. A financial institution faces costs in deviating from this level. If it lends more than this level, part of the debt is unsecured and it faces default risk on this unsecured portion. If it lends less, the cost arises from foregone profit opportunities. We assume this cost, $\Omega_{t}$, is quadratic in the deviation of real debt from its optimal level ${ }^{1}$ :

$$
\Omega_{t+i}=\left(\frac{Z_{t+1} / P_{t+i}-K_{t+i}}{K_{t+i}}\right)^{2} K_{t+i}
$$

where $Z_{t+1}$ is the nominal value of a new debt contract set at time $t$ which will be in force from period $t+1$, and $P$ is the price level.

When a financial institution is able to reset the value of its outstanding contracts, it does so to minimize the cost of the debt deviating from its optimal value over the expected contract period:

$$
\min _{Z_{t+1}} E_{t} \sum_{i=1}^{\infty}[\beta(1-\phi)]^{i} \Omega_{t+i}
$$

where $\beta$ is the firm's discount rate. The first-order condition is

$$
\sum_{1}^{\infty}[\beta(1-\phi)]^{i} \frac{1}{P_{t+i}}\left(\frac{Z_{t+1} / P_{t+i}-K_{t+i}}{K_{t+i}}\right)=0
$$

In what follows we assume $K_{t}$ is constant. The steady state ratio of the real value of a new contract ${ }^{2}, Z^{R}$ to collateral is then:

$$
\frac{Z^{R}}{K}=\frac{1-\frac{\beta(1-\phi)}{\Pi^{2}}}{1-\frac{\beta(1-\phi)}{\Pi}}
$$

where symbols without time subscripts indicate steady state values. If steady state inflation $\Pi$ is positive, this ratio is greater than unity. When banks reset the debt they choose a value higher than current collateral to make up for future inflation. In what follows, we only consider a steady

\footnotetext{
${ }^{1}$ To continue the analogy with the Calvo model, compare this with Rotemberg's (1987) assumption of a quadratic cost of deviating from the optimal price.

${ }^{2}$ In the steady state the nominal value of a contract and the price level will be growing at the same rate hence their ratio, the real value of the contract, will be constant
} 
state with zero inflation, in which case linearizing (3) gives

$$
z_{t+1}-E_{t} p_{t+1}=E_{t}\left\{\frac{[1-B(1)] F}{B(F)} \pi_{t+1}\right\}
$$

where lower case letters denote log deviations from steady state, $F$ is the forward shift-operator $\left(F^{i} x_{t}=x_{t+i}\right)$ and $B(F)=1-\beta(1-\phi) F$. This condition gives the expected value of a new real debt contract at time $t+1$ in terms of the expected path of inflation.

To develop the intuition behind this equation, assume that inflation follows a first-order autoregressive process with positive persistence ${ }^{3}$,

$$
\pi_{t}=\rho \pi_{t-1}+\varepsilon_{t} ; \quad \rho \geq 0
$$

where $0<\rho<1$ and $\varepsilon_{t}$ is a white noise error. Then (5) can be rearranged to give

$$
z_{t+1}-E_{t} p_{t+1}=\zeta \pi_{t} ; \quad \zeta \geq 0
$$

where $\zeta=\beta(1-\phi) \rho^{2}(1-\beta(1-\phi) \rho)^{-1}$ is increasing in $\rho$. If inflation is above its steady state value, the more persistent is inflation, the higher the real value of the contract chosen by financial institutions when they reset the contract's value in nominal terms since the faster it will be eroded.

\section{$2 \quad$ Aggregate debt}

At time $t$, a proportion $\phi(1-\phi)^{i}$ of financial institutions will have reset their contracts at time at time $t-i$ and have not had the opportunity to reset them since. So we can sum over all contracts and all financial institutions to obtain the real value of aggregate debt at the end of period $t$

$$
D_{t+1}=\frac{\phi}{P_{t+1}} \sum_{i=0}^{\infty}(1-\phi)^{i} Z_{t+1-i}
$$

\footnotetext{
${ }^{3}$ Of course, when embedded in a larger model, inflation will in general be determined endogenously; but $\mathrm{AR}(1)$ reduced forms for inflation arise quite commonly when there is some structural stickiness in the inflation process (see, for example, Clarida et al, 1999; Wright, 2004)
} 
Linearizing this gives

$$
d_{t+1}+p_{t+1}=\frac{A(1)}{A(L)} z_{t+1}
$$

where $A(L)=1-(1-\phi) L$ and $L$ is the lag operator $\left(L^{i} x_{t}=x_{t-i}\right)$.

Substituting for $z_{t+1}$ from (5) gives:

$$
\Delta d_{t+1}+\pi_{t+1}=\phi E_{t}\left\{\frac{1}{B(F)} \pi_{t+1}\right\}-\phi d_{t}
$$

Again, the intuition behind this equation can clarified by assuming that inflation follows the $\mathrm{AR}(1)$ process in (6) We can then rewrite (10) as

$$
\Delta d_{t+1}+\pi_{t+1}=\xi E_{t} \pi_{t+1}-\phi d_{t}
$$

and with further rearrangement obtain

$$
\Delta d_{t+1}+\pi_{t+1}=\left[\xi \rho+\phi \frac{C(L)}{A(L)}\right] \pi_{t}
$$

where

$$
\xi=\frac{\phi}{1-\beta(1-\phi) \rho}
$$

and $C(L)=1-\xi \rho L$

The left-hand side of (12) is the nominal value of debt issued during pe$\operatorname{riod} t$. The first term in the square brackets on the right-hand side captures the adjustment of new nominal debt contracts to the current deviation of real debt from its optimal value (given by collateral). If, for example, inflation was high at some point in the past, the impact of even a temporary shock will, given the autoregressive process for inflation, have a permanent impact on the price level, and hence the average real value of debt will have been reduced below the real value of underlying collateral (with the degree of the reduction being greater, the more persistent is inflation). As a result, new debt contracts will involve a degree of catch-up, to bring debt back up to collateral.

The second term in square brackets captures the impact of expected future inflation on the optimal value of the new contract. Given the assumed $\operatorname{AR}(1)$ nature of inflation, this will in turn be a function of the current inflation rate. 


\section{$3 \quad$ Floating and fixed rates}

The interest rate payable on debt can be either floating or fixed. If some proportion $\Psi$ of borrowers holds fixed rate debt, the average rate payable by credit-constrained borrowers on outstanding debt will be

$$
R_{t}^{D}=\Psi R_{t}^{F}+(1-\Psi) R_{t}
$$

where $R_{t}$ is the the short-term nominal interest rate ${ }^{4}$ and $R_{t}^{F}$ the nominal interest rate payable on fixed debt. Financial institutions will choose the (fairly priced) fixed rate on a particular debt contract, $R_{t}^{z}$, as the average of expected nominal rates over the duration of the contract:

$$
\begin{aligned}
R_{t}^{z} & =E_{t} \frac{\sum_{i=1}^{\infty}(1-\phi)^{i} R_{t+i}}{\sum_{i=1}^{\infty}(1-\phi)^{i}} \\
& =E_{t} \frac{A(1)}{A(F)} R_{t+1}
\end{aligned}
$$

The average fixed rate $R_{t}^{f}$ payable by borrowers will then be

$$
\begin{aligned}
R_{t}^{F} & =\phi R_{t}^{z}+\phi(1-\phi) R_{t-1}^{z}+\phi(1-\phi) R_{t-2}^{z}+\ldots \\
& =\phi \sum_{i=0}^{\infty}((1-\phi) L)^{i} R_{t}^{z} \\
& =\frac{A(1)}{A(L)} R_{t}^{z}
\end{aligned}
$$

Linearizing around a steady state where $R$ is constant so $R^{D}=R^{F}$ gives

$$
\begin{aligned}
r_{t}^{D} & =\Psi \frac{A(1)}{A(L)} r_{t}^{z}+(1-\Psi) r_{t} \\
& =E_{t}\left[\Psi \frac{A(1)^{2}}{A(L) A(F)} F+(1-\Psi)\right] r_{t}
\end{aligned}
$$

The system for debt then consists of two endogenous variables $r_{t}^{D}$ and $d_{t}$, two equations (10) and (20) which relate them to exogenous variables $r_{t}$ and $\pi_{t}$. We have introduced two new parameters, $\phi$, the probability of a

\footnotetext{
${ }^{4}$ We assume risk neutrality of financial institutions as a simplifying assumption. Any spread between the central bank's target rate and the floating debt rate is also assumed constant and normalised to zero.
} 
financial institution being able to reset its contract (the average length of contracts being given by $\frac{1}{1-\phi}$ ) and $\Psi$, the proportion of debtors in fixed rate schemes. It is straightforward to extend the model to allow for the average length of fixed rate debt to be different from the average life of a floating rate contract.

\section{Implications for System Dynamics}

We can write our two additional equations in the general form

$$
\begin{aligned}
A(L) d_{t+1} & =E_{t}\left[G(L, F) \pi_{t}\right] \\
A(L) r_{t}^{D} & =E_{t}\left[H(L, F) r_{t}\right]
\end{aligned}
$$

where

$$
\begin{aligned}
G(L, F) & =\left(\frac{\phi}{B(F)}-1\right) F \\
H(L, F) & =\Psi \frac{A(1)^{2}}{A(F)} F+(1-\Psi) A(L)
\end{aligned}
$$

Both variables share the common first-order AR lag polynomial, $A(L)$. Sticky debt contracts thus increase the order of autoregressive dynamics in the system by one. Without introducing undue additional complexity to the model, this nonetheless raises the possibility of more "interesting" dynamic adjustment processes than those which arise from most standard dynamic general equilibrium models.

\section{Bibliography}

Aoki, Kosuke, James Proudman and Gertjan Vlieghe, (2002), "House prices, consumption, and monetary policy: a financial accelerator approach", Bank of England Working Paper 169.

Clarida, R, Jordi Gali and Mark Gertler, (1999), "The Science of Monetary Policy: A New Keynesian Perspective", Journal of Economic Literature 37 (4), pp.1661-1707.

Kiyotaki, Nobuhiro and John Moore, (1997), "Credit Cycles", Journal of Political Economy 105, pp.211-248.

Mankiw, Gregory N, (2000), "The Savers-Spenders Theory of Fiscal Policy", American Economic Review 90 (2), pp.120-125. 
Rotemberg, Julio (1987), "New Keynesian Microfoundations", NBER Macroeconomics Annual.

Wright, Stephen, (2004), "Monetary Stabilisation with nominal asymmetries", Economic Journal 114 (492), pp.196-222. 